\title{
Barriers to smart waste management for a circular economy in China
}

Abraham Zhang, V. G. Venkatesh, Yang Liu, Ming Wan, Ting Qu and Donald Huisingh

The self-archived postprint version of this journal article is available at Linköping University Institutional Repository (DiVA):

http://urn.kb.se/resolve?urn=urn:nbn:se:liu:diva-161117

N.B.: When citing this work, cite the original publication.

Zhang, A., Venkatesh, V. G., Liu, Y., Wan, M., Qu, T., Huisingh, D., (2019), Barriers to smart waste management for a circular economy in China, Journal of Cleaner Production, 240, UNSP 118198. https://doi.org/10.1016/j.jclepro.2019.118198

Original publication available at:

https://doi.org/10.1016/j.jclepro.2019.118198

Copyright: Elsevier

http://www.elsevier.com/

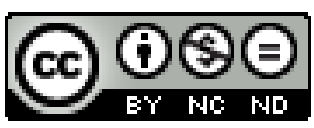




\section{Journal Pre-proof}

Barriers to smart waste management for a circular economy in China

Abraham Zhang, V.G. Venkatesh, Yang Liu, Ming Wan, Ting Qu, Donald Huisingh

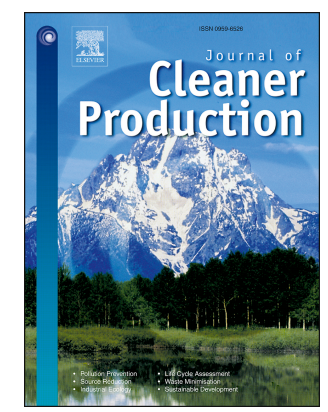

PII:

S0959-6526(19)33068-9

DOI: $\quad$ https://doi.org/10.1016/j.jclepro.2019.118198

Reference: JCLP 118198

To appear in: Journal of Cleaner Production

Received Date: 5 March 2019

Revised Date: 9 July 2019

Accepted Date: 26 August 2019

Please cite this article as: Zhang A, Venkatesh VG, Liu Y, Wan M, Qu T, Huisingh D, Barriers to smart waste management for a circular economy in China, Journal of Cleaner Production (2019), doi: https:// doi.org/10.1016/j.jclepro.2019.118198.

This is a PDF file of an article that has undergone enhancements after acceptance, such as the addition of a cover page and metadata, and formatting for readability, but it is not yet the definitive version of record. This version will undergo additional copyediting, typesetting and review before it is published in its final form, but we are providing this version to give early visibility of the article. Please note that, during the production process, errors may be discovered which could affect the content, and all legal disclaimers that apply to the journal pertain.

() 2019 Published by Elsevier Ltd. 


\title{
Barriers to Smart Waste Management for a Circular Economy in China
}

Abraham Zhang a,b (abraham.zhang@aut.ac.nz), V G Venkatesh c, Yang Liu d,e,f (Corresponding author: yang.liu@liu.se), Ming Wan ${ }^{\mathrm{g}, \mathrm{d}}$, Ting Qu ${ }^{\text {h,d }}$ (Corresponding author: quting@jnu.edu.cn), Donald Huisingh ${ }^{\mathrm{i}}$

a Auckland University of Technology (AUT) Business School, AUT University, Private Bag 92006, Auckland 1142, New Zealand

${ }^{\mathrm{b}}$ Lumen Research Institute, Excelsia College and Indiana Wesleyan University, 69-71 Waterloo Road, Macquarie Park, NSW 2113 Australia

${ }^{c}$ School of Management and Marketing, The University of Waikato, Hamilton 3240, New Zealand (E-mail: vgv1976@gmail.com)

d Institute of Physical Internet, Jinan University (Zhuhai Campus), Zhuhai, 519070, China

e Department of Management and Engineering, Linköping University, SE-581 83 Linköping, Sweden

${ }^{\mathrm{f}}$ Department of Production, University of Vaasa, 65200 Vaasa, Finland

${ }^{\mathrm{g}}$ School of Management, Jinan University, 510632, Guangzhou, PR China

${ }^{\mathrm{h}}$ School of Intelligent Systems Science and Engineering, Jinan University (Zhuhai Campus), Zhuhai, 519070, China

${ }^{\mathrm{i}}$ The Institute for a Secure and Sustainable Environment, University of Tennessee, Knoxville, USA

\begin{abstract}
Waste management requires a new vision and drastic improvements for a transition to a zerowaste circular economy. In reality, however, many economies are producing more and more waste, which poses a serious challenge to environmental sustainability. The problem is enormously complex as it involves a variety of stakeholders, demands behavioral changes, and requires a complete rethinking of the current waste management systems and the dominant liner economic model. Smart enabling technologies can aid in a transformation of waste management toward a circular economy, but many barriers persist. This study first
\end{abstract}


shortlists twelve important barriers to smart waste management in China based on interviews with experienced practitioners. It then prioritizes these barriers through a scientific prioritization technique, fuzzy Decision-Making Trial and Evaluation Laboratory (DEMATEL), based on the survey data from three representative stakeholders. It identified three key causal barriers: the lack of regulatory pressures, the lack of environmental education and culture of environmental protection, and the lack of market pressures and demands. Practical and theoretical implications were discussed based on the research results and findings.

Keywords: smart enabling technologies; Internet of Things, IoT; smart waste management; circular economy; circular supply chain management Article Classification: Research article 


\section{Introduction}

As the world moves towards sustainable development, smart cities integrate cyberinfrastructure to foster all-around economic growth, including better quality of life and more efficient management of resources (Albino et al., 2015). The increasing quantity of waste and its management are major concerns to many cities and regions, due to the ineffective and inefficient operations of waste collection and management (Jacobsen et al., 2018). However, smart cities are increasingly focusing upon developing solutions to solve these problems by using smart enabling technologies, such as the 'Internet-of-Things,' (IoT), big data, and artificial intelligence (IA) (Esmaellian et al., 2018). These technologies are expected to change the landscape of urban development and to support progress towards the aspiration for a circular economy (CE) (Ellen MacArthur Foundation, 2013; Ghisellini et al., 2016). CE is now widely recognized as a sustainable alternative to the dominant liner (extract-make-dispose) economic model. A transition to $\mathrm{CE}$ requires a paradigm shift to an innovative and more sustainable supply chain ecosystem (Zanella et al., 2014; Farooque and Zhang, 2017; Batista et al., 2018).

At the micro level, waste management should be based upon a normative foundation to the integrative concept of sustainability (Taelman et al., 2018). The use of smart enabling technologies was identified as one of the pathways towards that sustainability. The term smart waste management has been used, albeit sporadically, in the extant literature (Glouche and Couderc, 2013; Schafer, 2014; Omar et al. 2016). However, the concept has received limited attention and has not been clearly defined, despite its documented potential. This research team took first steps to define smart waste management as utilizing smart enabling technologies for more efficient, effective and sustainable operations of waste management. Such smart enabling technologies include but are not limited to: IoT, big data analytics, cloud 
computing, cyber-physical system, and artificial intelligence. These approaches can help to facilitate the efficient monitoring, collection, separation, and transportation of waste for value recovery and proper disposal. In recent years, interest has spread to data acquisition and communication technologies as well. They help to monitor truck/trash bin load status, optimize truck routes, and to fine-tune the collection schedule, by using dynamic models (Anagnostopoulos et al., 2017; Liu et al., 2019).

The implementation of smart waste management systems is still in the embryonic stage (Fuss et al., 2018). Arguably, it is an increasingly complex problem that involves citizens' behavior, product designers, producers and policy-makers (Aljerf, 2018; Zhang et al., 2019) and, therefore, involves infrastructure- and management-related aspects of operationalizing the technologies. Nevertheless, modern solutions are relatively new compared to other practices in waste management. There are some issues, such as data security, which may currently, impose constraints on the capabilities of smart waste management systems (Schafer, 2014).

Meanwhile, many authors have called for all dimensions of waste management to be explored through inter-disciplinary studies: including the urban science, social science, engineering, ecological, economic and ethical domains. Recent studies only focus on describing the technologies involved and their applications (Aljerf, 2018; Esmaellian et al., 2018); as yet, there is little discussion of governmental policies, business models, and management decisions that drive or impede the deployment of appropriate technologies. Reports on barriers to the use of smart waste management systems are not present in the literature.

Particularly, the Chinese government has been keen on promoting CE and has legislated CE as part of its national development policy in 2008 (Su et al., 2013). The Chinese government and many enterprises are keen on engaging in $\mathrm{CE}$ solutions. The $\mathrm{CE}$ initiative has commenced in 27 provinces covering sectors such as metallurgy, transportation, and 
pharmaceuticals and textiles ( $\mathrm{Li}$ and Lin, 2016). The leading cities in CE implementation include Huangshan, Sanya, Zhuhai, Dalian, Guangzhou, Qingdao and Yantai. In addition, China has accelerated CE implementation that leads to the development of eco-cities and industrial parks in the last two decades by working with international partners. Such prominent eco-cities are: Dongtan, Sino-Singapore Tianjin Eco-city, and Suzhou New District. Recently, the Chinese state council launched a new program to develop 10 zerowaste cities to minimize solid waste generation and maximize recycling in the urban area (Huo, 2019).

However, there continues to be many barriers to an effective and efficient transition to CE in China (Mathews and Tan, 2016). It is therefore, an interesting avenue of research to investigate the specific barriers to implementation of smart waste management systems in China. Therefore, this research, was designed and performed to inform policy and managerial decision-making. Against this background, this research addressed the following two research objectives:

- To identify the key barriers to smart waste management for the transition to a CE in China

- To understand how the key barriers, interact and how to involve all stakeholders to make effective transitions to more ecologically, economically and ethically sound waste management systems.

The research problem is challenging due to a multidisciplinary nature which requires expertise in waste management, logistics, decision sciences, public policy, legislation, environmental science and technologies. The concerned issue in practice is enormously complex as it involves a variety of stakeholders including many government agencies, producers, consumers, technology providers and waste management organizations. A 
sustainable solution demands behavioral changes and requires a complete rethinking of the current waste management systems and the dominant liner economic model.

The main contributions of this research were based upon the exploration of the barriers to smart waste management at the operational level. The observed cause-effect relationships provided a holistic insight into the barriers to the implementation of smart waste management solutions. The findings provide insights to all stakeholders, including technology service providers, users, governments, monitoring institutions, industry associations and the public, for overcoming the barriers. They also identified key inputs for improving waste management policy frameworks. The study was contextualized in China, which has embraced sustainability as part of its national agenda (Su et al., 2013). However, the research problem is also relevant to many other countries which strive to use smart enabling technologies to improve their waste management systems, especially to those which have embraced a CE vision.

The remainder of the paper is organized as follows. Section 2 reviewed the relevant literature. Section 3 explained the methodology and data collection procedures. Section 4 presented results, analysis, and findings. Section 5 discussed policy and managerial implications. Section 6 concluded the research and presented the recommendations of how to proceed, in the future.

\section{Literature review}

Waste management is strategic for keeping resources circulating. The purpose of circularity of resources is to incorporate the perspectives of industrial symbiosis, service ecosystems, resource-based productivity, and functional alignment to help to ensure that societies will function sustainably (Chertow, 2007; Seuring and Muller, 2008; Sarkar, 2013; Batista et al., 2018). In line with CE objectives, improved waste management is primarily focused upon 
exploring the avenues to control or to decrease waste generation; it also has waste recycling, waste reclamation foci (Park et al., 2010; Jacobsen et al., 2018). Nevertheless, major decisions about waste management are complex due to the intricate patterns behind solid waste. Also, its operating frameworks involve multiple stakeholders, including property management, local governments, municipalities, impacts upon and involvement of the citizens, engagement of technical experts, and its frameworks, which directly affect the sustainability of urban ecosystems (Othman et al., 2013). Waste management needs to include managing technical inputs, evaluating short and long-term cost-benefit decisions, and in addressing social conflicts (Chi et al., 2011) and within the conceptual framework of CEs, wherein wastes are considered to be resources (Veleva et al., 2017).

Waste management practices are undergoing a transformation from an oversimplified procedure of collection and sorting to a sustainable system which balances product/service system designs, material's recovery/energy recovery and end-of-life management of currently wasted resources via, waste reduction practices, biological and thermal processes, and material recycling techniques (Arena, 2012; Jacobsen et al., 2018). Waste management practices influence operational decisions by requiring a focus on product design and restoration activities at various stages in supply chain (Jensen and Remmen, 2017). Thus, the system manages and adapts to a complex setting by processing information, which facilitates environmental effectiveness, social acceptability, and economic affordability (Xiao et al., 2018). Eventually, firms may face technical challenges to integrating product- and restoration-related information (Govindan and Hasnagic, 2018).

Smart enabling technologies in the CE realm use electronics, software, sensors, and actuators to process and exchange data for improved results (Atzori et al., 2010; Anagnostopoulos et al., 2017). Esmaeilian et al. (2018) recognized four categories of smart waste management systems technology: the development of data acquisition and sensor-based technologies, 
communication and data transmission technologies, field experiment technology, and technologies for setting and scheduling truck routes. These technologies use RFID tags, NFC sensors, GPS, etc. to facilitate real-time data collection and to inform effective decisionmaking in restoration activities.

Recently, geographic information systems (GIS) and dynamic scheduling with robust algorithms have also been integrated into the decision support systems. Process architecture, social context, and experimental data are the smart components of GIS, which control the waste management process (Cerchecci et al., 2018). Using artificial intelligence techniques including deep learning and machine learning, these smart components process a large volume of data to provide real-time information and to support effective decision-making with less human involvement (Guiterrez et al., 2015; de Souza Melaré et al., 2017; Jha et al., 2017). They facilitate the tracking of waste collection and the optimization of container loads and vehicle routes using a decision-support system. In some cases, the data can be used for service provisioning as well (Hong et al., 2014). This kind of transparent information flow makes consumers more positive to participate in the waste management process (Hazen et al., 2017).

There are some successful cases in smart waste management. The companies like Compology, Sensoneo and RecycleSmart improve waste management using IoT sensor based technologies and web-based software to localize, monitor and measure the fullness level of containers, termed as smart bin technology, allowing transportation service providers to plan their logistics operations effectively (Hong et al., 2014). Other smart enabling technologies including big data analytics and cloud computing have also been deployed for better understanding waste sources and more effective waste management (Aazam et al., 2016). Table 1 provides an overview on the principles and strategies of the main smart enabling technologies used in waste management. 
Table 1: Smart enabling technologies make waste management smarter

\begin{tabular}{|c|c|}
\hline $\begin{array}{l}\text { Smart enabling } \\
\text { technologies }\end{array}$ & Smart technical principles and strategies \\
\hline $\begin{array}{l}\text { IoT including RFID } \\
\text { tags, NFC sensors and } \\
\text { GPS sensors }\end{array}$ & $\begin{array}{l}\text { IoT performs sensing, data collection, storage, and processing by } \\
\text { connecting physical or virtual devices to the Internet. IoT based } \\
\text { waste management system can provide real-time data on the status } \\
\text { of smart trash cans and residents' information. This helps optimize } \\
\text { garbage collection and vehicle path planning. }\end{array}$ \\
\hline Cloud Computing & $\begin{array}{l}\text { Data stored in the cloud are accessible to all the involved } \\
\text { stakeholders to aid decision making. Analysis and planning can start } \\
\text { from as soon as waste is generated to recycling and value recovery } \\
\text { activities. }\end{array}$ \\
\hline Big data analytics & $\begin{array}{l}\text { Big data analytics can be used to reduce waste generation and } \\
\text { improve its management. Combined with geographic and socio- } \\
\text { economic data, big data analytics can help in understanding spatial } \\
\text { distribution of waste. }\end{array}$ \\
\hline $\begin{array}{l}\text { Cyber-based Decision } \\
\text { Support Systems }\end{array}$ & $\begin{array}{l}\text { Cyber-based Decision Support System can support public decision- } \\
\text { makers in designing and planning waste management system and to } \\
\text { optimize and monitor its carbon footprint. }\end{array}$ \\
\hline $\begin{array}{l}\text { Artificial intelligence } \\
\text { including machine } \\
\text { learning and deep } \\
\text { learning }\end{array}$ & $\begin{array}{l}\text { Artificial intelligence can help identify patterns in waste and the } \\
\text { behaviors of those who generate waste, to support effective } \\
\text { decision-making. }\end{array}$ \\
\hline
\end{tabular}

Despite of some successful applications, overall the use of smart waste management systems is still limited due to high investment costs, divergent processes in the waste stream, and lack of policy support (de Souza Melaré et al., 2017). There needs to be more studies on the use of smart enabling technologies to improve waste management. The needs are particularly urgent for the developing countries as they face major challenges in managing waste due to 
rapid urbanization, economic development, and rising living standards (Xu et al., 2015). The extant literature is silent on the barriers to implementation of smart waste management systems in developing countries.

In recent years in China, municipal solid waste was the most challenging environmental concern, as researchers reported incremental growth of 5-10 percent increase of solid waste generated per year (Xu et al., 2015; Chu et al., 2017). The main sources of waste are residential households, markets, commercial complexes, public areas, streets, and temples (Gu et al., 2015). Both formal and informal recycling networks which handle recycling and waste disposal face their own challenges. Source separation pilot programs launched in 2000 have experienced poor results, and the weakness of the recycling system was mainly attributed to inadequate infrastructure (Tai et al., 2011). Additionally, policies and technologies imported from other countries were not adapted effectively in the national context, especially due to organic waste, which cannot be treated by landfill or incineration (Xiao et al., 2018). However, in an effort to improve waste management system, Chinese officials have recently shifted focus to community-based waste management programs. The government is also keen to promote an integrated system under the national strategy ( $\mathrm{Gu}$ et al., 2015).

This literature review highlights that fact that implementation of smart waste management solutions in China faces many challenges. While existing studies explored technological details, the management literature about smart waste management is only just emerging (Zhang et al., 2019). To narrow the knowledge gap, the researchers of this paper adopted a mixed-methods approach, in two stages, to study the barriers and their interrelationships, which are absent from extant literature. 


\section{Methodology and data collection}

\subsection{A Mixed-methods Approach}

In recent years, many researchers have advocated a mixed-methods approach to overcome the limitations of both qualitative and quantitative methods in business research (Gölcük and Baykasoğlu, 2016; Govindan and Chaudhuri, 2016; Shao et al., 2016). A mixed-methods approach is suitable for achieving the research objectives proposed in Section 1. The first objective required a qualitative exploratory method to shortlist the key barriers to smart waste management for a $\mathrm{CE}$ in China. The second research objective required a quantitative prioritization technique to identify and rank the most significant barriers and to investigate how they interact.

The qualitative phase of the research employed semi-structured interviews. In a semistructured interview method, open-ended questions were used to give interviewees freedom to share their knowledge on the topic. At the same, it helped the interviewers to maintain the focus of the conversations by following pre-defined questions (Bell et al., 2018). Before an interview, all interviewees were provided with an information sheet which explained the concepts of $\mathrm{CE}$ and smart waste management and the potential future roles of smart enabling technologies, including IoT. The interview protocol is included in Appendix 1.

The information sheet provided to the interviewees included an initial list of barriers. The researchers compiled the list based on a survey of news reports and academic literature (Shi et al., 2008; Walker et al., 2008; Giunipero et al., 2012; Zhu et al., 2014; Rauer and Kaufmann, 2015; Kaur et al., 2017; Venkatesh et al., 2017; Masi et al., 2018; Govindan and Hasanagic, 2018; Mangla et al., 2018). These barriers included, a lack of capacity for innovation, difficulty in securing financial resources, technologies changing too fast, difficulty in technology integration, lack of accountability, and weak enforcement of relevant 
laws and regulations. The interviewees were requested to revise the listed barriers and to suggest ones not included in the initial list.

In the quantitative phase, the researchers used the fuzzy Decision-Making Trial and Evaluation Laboratory (DEMATEL) method. DEMATEL is a multi-criteria decision-making method for identifying and prioritizing the causal relationships among the components of a system. Interpretive structural modelling (ISM) and analytic hierarchy process (AHP) can also be used to analyze the relationships among interdependent factors. However, DEMATEL has the advantage of helping researchers to visualise the causal relationships and to reveal the overall degree of influence wielded by the respective factors (Venkatesh et al., 2017). For this reason, DEMATEL has been widely used in sustainability-related studies (Zhu et al., 2014; Shao et al., 2016; Bai et al., 2017; Venkatesh et al., 2017). Fuzzy DEMATEL, a fuzzy set extension to the standard DEMATEL technique, was used in this research. Fuzzy DEMATEL has the advantage of handling the inherent biases and vagueness in human judgments ( $\mathrm{Wu}$ and Lee, 2007; Lin, 2013). The researchers applied the fuzzy DEMATEL technique by using the following steps, outlined in Venkatesh et al. (2017), to analyze the barriers to smart waste management.

Step 1: Surveying the respondents to structure a pair-wise comparison matrix

In this step, each participant was asked to assess the impact barrier $i$ has on barrier $j$ on a scale from 0 to $4(0=$ no influence, $1=$ very low influence, $2=$ low influence, $3=$ high influence and 4 = very high influence).

Step 2: Obtaining the fuzzy initial direct relation matrix (A)

To capture the fuzziness in the judgments, triangular fuzzy numbers (TFNs) (Seçme et al., 2009) were used to represent linguistic variables. Each TFN was expressed as a triplet $(e, f, g)$ to explain a fuzzy event. The parameters $e, f$, and $g$ specified the smallest possible, the most 
promising, and the largest possible value respectively. A triangular fuzzy number $\tilde{M}$ from universe of discourse to [0,1] is shown in Figure 1 (Deng, 1999).

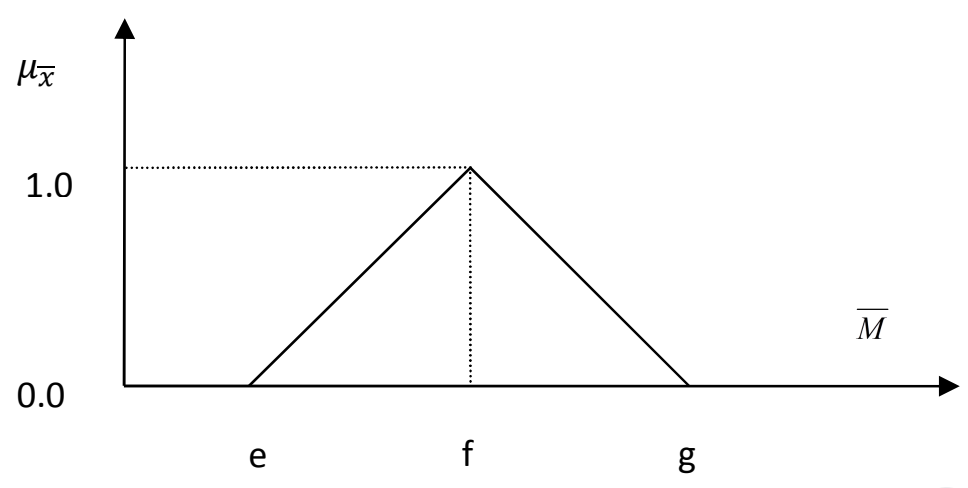

Figure 1: Triangular fuzzy numbers represent linguistic variables

Table 2 shows the fuzzy linguistic scale used (Wu, 2012; Venkatesh et al., 2017) in this study to convert impact scores to triangular fuzzy numbers.

Table 2: Fuzzy linguistic scale converts impact scores to triangular fuzzy numbers

\begin{tabular}{|l|l|l|}
\hline $\begin{array}{l}\text { Impact } \\
\text { score }\end{array}$ & $\begin{array}{l}\text { Description of } \\
\text { linguistic variable }\end{array}$ & $\begin{array}{l}\text { Equivalent triangular } \\
\text { fuzzy numbers }\end{array}$ \\
\hline 0 & No influence (No) & $(0,0,0.25)$ \\
\hline 1 & Very low influence (VL) & $(0,0.25,0.5)$ \\
\hline 2 & Low influence (L) & $(0.25,0.5,0.75)$ \\
\hline 3 & High influence (H) & $(0.5,0.75,1.0)$ \\
\hline 4 & Very high influence $(\mathrm{VH})$ & $(0.75,1.0,1.0)$ \\
\hline
\end{tabular}

Suppose $\mathrm{x}_{\mathrm{ij}}^{\mathrm{k}}=\mathrm{e}_{\mathrm{ij}}^{\mathrm{k}}, \mathrm{f}_{\mathrm{ij}}^{\mathrm{k}}, \mathrm{g}_{\mathrm{ij}}^{\mathrm{k}}$ where $1 \leq \mathrm{k} \leq \mathrm{K}$ to be the fuzzy evaluation that the $\mathrm{k}^{\text {th }}$ expert gave about the degree to which barrier $i$ impacts barrier $j$. If ' $\mathrm{K}$ ' is the number of participants in our study to estimate causality between the identified $\mathrm{n}$ study barriers, then inputs given by the participants result in an $\mathrm{n} \times \mathrm{n}$ matrix, i.e. ${ }^{X^{k}}=x_{i j}^{k}$; where $\mathrm{k}=1,2,34 \ldots \mathrm{n}$ (number of experts in a decision panel).

$$
a_{i j}=\frac{1}{k \sum x^{\mathrm{k}} \mathrm{ij}}
$$


Following that, the defuzzification process was used to convert the fuzzy numbers to crisp numbers, as those fuzzy numbers were not appropriate for the matrix operations. The researchers defuzzified the fuzzy direct relation matrix using equation (2):

$$
\mathrm{I}_{\mathrm{T}}=\frac{1}{6}(e+4 f+g)
$$

Step 3: Constructing the normalized initial direct relation matrix (D)

$$
\begin{aligned}
& \mathrm{m}=\min \left[\frac{1}{\max \sum_{\mathrm{j}=1}^{\mathrm{n}}\left|\mathrm{a}_{\mathrm{ij}}\right|}, \frac{1}{\max \sum_{\mathrm{i}=1}^{\mathrm{n}}\left|\mathrm{a}_{\mathrm{ij}}\right|}\right] \\
& \mathrm{D}=\mathrm{m} \times \mathrm{A}
\end{aligned}
$$

Step 4: Obtaining the total relation matrix

$$
\mathrm{T}=(\mathrm{I}-\mathrm{D})^{-1}
$$

Where, I: Identity matrix; T: Total relation matrix

$$
\mathrm{T}=\left[\mathrm{t}_{\mathrm{ij}}\right]_{\mathrm{n} \times \mathrm{n}}
$$

Step 5: Calculating the sum of rows (R) and the sum of columns (C)

$$
\begin{aligned}
& R=\left[\sum_{j=1}^{n} t_{i j}\right]_{n \times 1} \\
& C=\left[\sum_{i=1}^{n} t_{i j}\right]_{1 \times n}
\end{aligned}
$$

$\mathrm{R}$ represents the overall impact that barrier $i$ has on barrier $j . \mathrm{C}$ stands for the overall effect experienced by barrier $i$ coming from barrier $j$.

Step 6: Generating the cause-effect diagram

A cause-effect diagram was generated using the data set of $(\mathrm{R}+\mathrm{C} ; \mathrm{R}-\mathrm{C}) .(\mathrm{R}+\mathrm{C})$ is the horizontal axis and it measures the prominence of a barrier, indicating its total effects in terms of influenced and influential power. (R-C), the vertical axis, explains the causal-effect relationship between the barriers. A barrier falls into the cause group if its (R-C) value is positive. Conversely, a barrier falls into the effect group if its $(\mathrm{R}-\mathrm{C})$ value is negative $(\mathrm{Wu}$ 
and Lee, 2007; Lin, 2013). In addition, significant relationships were mapped on the causeeffect diagram by arrows to highlight the impact that one barrier has on another. The threshold value for a significant relationship was calculated by adding two standard deviations to the mean of the total relation matrix (Zhu et al., 2014).

\subsection{Data Collection}

The data were collected in Southern China using the Mandarin Chinese language. The data collection instruments were first developed in English, with reference to academic literature, and were then translated into Chinese by two experienced researchers who are fluent in both English and Chinese. To ensure content validity, a pilot test was done to obtain feedback from practitioners. Subsequently, minor revisions were made to the data collection instruments to remove ambiguity and to avoid potential misunderstanding. To ensure data validity and reliability, the researchers required that all the research participants had multiple years of experience with smart waste management equipment/systems. The researchers assured all research participants that the data gathered from them were for academic research purposes only. All research participants voluntarily supported the research. The researchers who collected data were knowledgeable in the area of smart waste management. They validated the data provided by all research participants and asked for explanations and revisions of data, when in doubt.

In the qualitative phase, the authors sent an email invitation and an interview information sheet to twenty potential participants. The authors applied a purposeful sampling process (Gentles et al., 2015) to engage the senior management of organizations and their knowledgeable employees who had experience with smart waste management applications. In total, fourteen respondents agreed to participate in the research. All these respondents were interviewed in August or September 2018, either by a face-to-face meeting in their offices or over the phone. Each interview lasted about 30-50 minutes. This phase of the research 
involved organizations of a variety of ownership types. Their industry types included government, healthcare, property development, logistics, and manufacturing. The profile of the research participants is provided in Appendix 2.

In the quantitative phase, the participants made pairwise comparisons among shortlisted barriers to judge their causal-effect relationships. The authors surveyed three representative organizations, each playing a different role in the use of smart waste management. Compared to obtaining data only from a single type of organization, this research design was more robust and it helped to mitigate potential biases from each role. The three organizations were: 1) A technology provider: a manufacturer and designer of smart waste management equipment/systems, including IoT-enabled smart bins, self-cleaning rubbish bins, and smart environmental management systems; 2) A technology user: a property development and construction firm which has been using smart waste management equipment/systems; 3) A governmental agency: it oversees environmental protection and waste management activities. It manages waste management contractors, drafts and enforces relevant regulations. Appendix 3 presents the profile of the participants.

\section{Results, Analysis and Findings}

\subsection{Smart Waste Management Barriers}

The qualitative phase of the research documented twelve important barriers. These barriers were chosen based on the input from the fourteen interviewees, because they were identified most frequently and were ascribed to be significantly important. They are described as follows:

B1 - Lack of knowledge of smart waste management: Smart enabling technologies, including IoT, are relatively new and their applications in waste management have only just 
been initiated in some organizations. Many organizations do not have knowledge or expertise in smart waste management. Consequently, they do not see the need or are not aware of the potential to improve waste management operations by implementing smart enabling technologies.

B2 - Lack of regulatory pressures: CE has been part of China's national development strategy for over a decade, but its implementation has only made modest progress (Mathews and Tan, 2016). Weaknesses in environmental regulations and enforcement have been identified as key barriers. There are seldom consequences for those who pollute and generate/dump waste. Due to this lack of regulatory pressures, organizations tend to continue the status quo of waste management, which is often a neglected part of supply chain operations management. They do not feel obliged to invest in the latest smart enabling technologies for improving waste management operations.

B3 - Lack of innovation capacity: Smart enabling technologies are relatively new and rapidly evolving. Organization leaders need enough capacity to innovate to successfully implement these technologies in waste management and to upgrade them when necessary, possibly in collaboration with technology providers. Many leaders lack the required innovation capacity or have no innovation culture that would allow them to develop it. This makes it difficult for them to be convinced of the need to provide the required economic and human resources and explore new opportunities for the use of smart enabling technologies in their waste management.

B4 - Difficulties in technologies and their applications: Smart enabling technologies have great potential, but their application raises multiple technological challenges. One of the most common barriers is the "difficulty in technology integration" (Hannan et al., 2015). It is an especially formidable difficulty when a supply chain or firm uses multiple technology platforms that are incompatible with each other. Another difficulty lies in the short life cycle 
of technological products. Due to the rapid pace of innovation in the technology sector, it is difficult for users to keep up with the never-ending product upgrades. In addition, there is a lack of automated waste classification and recognition technology.

B5 - Lack of market pressures and demands: A lack of market pressures and demands are serious obstacles in China, where most of the public does not care much about protecting the environment. Although, many people claim to care about it, their behavior speaks otherwise - littering is commonplace in many parts of the country. Given the uncertain economic benefits, organizations are unlikely to implement sustainability practices without stakeholder pressures (Kassinis and Vafeas, 2006; Luoma and Meixell, 2015). The same is true for improving waste management by investing in smart enabling technologies.

B6 - Cost and financial challenges: Many organizations have difficulty in securing financial resources for improving waste management. Furthermore, an organization often produces many types of waste, which make it difficult to treat each of them properly for value recovery. Partly due to the lack of scale economy in waste treatment, it is prohibitively costly for individual organizations to invest in smart enabling technologies for waste management.

\section{B7 - Lack of environmental education and culture of environmental protection: China}

incorporated environmental education into its national curricula, in recent years. However, the adult generations did not receive much environmental education. Their mindsets, habits and behavior often have no regard for environmental protection, and their behavior is difficult to change. Consequently, their irresponsible behavior, for example, not sorting waste before disposal, continues to negatively influence the younger generations and to undo the benefits of their environmental education at school. There is still a long way to go for China to instill environmental values in the hearts, minds, and actions of its citizens. 


\section{B8 - Lack of stakeholder cooperation, including service provider co-operation: Waste} management should be based on life cycle assessment (Morrissey and Browne, 2004). There is not enough stakeholder cooperation in the supply chain to encourage managers to adopt smart waste management. Stakeholder cooperation includes not only integration at the technological level, but also at the levels of shared responsibilities and aligned incentives and rewards (Wolf, 2011). There is also a lack of providers of smart services, even among governmental contractors, in the waste management industry.

B9 - The pursuit of short-term profitability instead of long-term sustainability: It is difficult to forecast and plan business objectives beyond the one-to-five years' time horizon (Giunipero et al., 2012). Implementing smart enabling technologies in waste management requires substantial investment, but the fruit of environmental sustainability may take years. It is a trade-off between short-term profitability and long-term sustainability. Many trade-off decisions by firms are short-term in nature (Wu and Pagell, 2011). The adoption of smart waste management is not likely when organizations only pursue their short-term economic interests.

B10 - Lack of cluster effect: Efficient waste management requires scale economy. Implementing smart waste management among a cluster of organizations can help to create a scale economy. Conversely, it is difficult for individual organizations to implement smart waste management solutions by themselves. Lack of the benefits of cluster effects, will remain a barrier until the implementation of smart waste management solutions has become widespread.

B11 - Lack of leadership commitment: Lack of leadership commitment is a common obstacle to many initiatives for business process improvement (Zhang et al., 2016). Leaders need to be committed not only to securing resources to invest in smart enabling technologies, but also to re-engineering business processes, which is required in the implementation stage. 
Lack of leadership commitment, therefore, could ground the boat of smart waste management on its journey to a CE.

B12 - Lack of proper standards of waste management: There are many types of waste, including food, electronic, plastics, construction, and hazardous. These require a variety of treatment methods for value recovery and proper management in CEs. Many governmental agencies and organizations are involved in the management and treatment of waste, and they have different requirements. As a result, lack of proper standards of waste management poses a challenge in the use of smart enabling technologies to automate the relevant activities.

\subsection{Fuzzy DEMATEL Analysis Results}

\subsubsection{Results from the Technology Provider's Perspective}

Table 3 presents the total relation matrix of the DEMATEL analysis of results from the perspective of the technology provider. B1, B2, .. and B12 in the table represent the barriers defined above. As stated in Section 3.1, the threshold value for a significant relationship was calculated by adding two standard deviations to the mean of the total relation matrix. Based on the results presented in Table 3, the threshold value was calculated to be 0.271 . The values greater than this were highlighted in bold in Table 3. They were also mapped in Figure 2 to indicate significant causal-effect relationships. Identifying significant relationships between the barriers is important for devising intervention plans to overcome the barriers. If a causal barrier in a significant relationship is removed, the effect barrier is likely to be automatically circumvented due to its dependency on the former.

Table 3. Total relation matrix shows the overall impact relationships among the barriers from the technology provider's perspective

\begin{tabular}{|l|l|l|l|l|l|l|l|l|l|l|l|l|}
\hline & B1 & B2 & B3 & B4 & B5 & B6 & B7 & B8 & B9 & B10 & B11 & B12 \\
\hline B1 & 0.111 & 0.135 & $\mathbf{0 . 2 7 5}$ & 0.236 & 0.189 & 0.023 & 0.179 & 0.235 & 0.251 & 0.160 & 0.110 & 0.196 \\
\hline B2 & 0.156 & 0.083 & 0.265 & 0.249 & 0.232 & 0.026 & 0.224 & $\mathbf{0 . 2 8 1}$ & $\mathbf{0 . 2 9 8}$ & 0.171 & 0.186 & 0.212 \\
\hline B3 & 0.101 & 0.047 & 0.101 & 0.208 & 0.169 & 0.018 & 0.101 & 0.159 & 0.195 & 0.127 & 0.059 & 0.071 \\
\hline
\end{tabular}




\begin{tabular}{|l|l|l|l|l|l|l|l|l|l|l|l|l|}
\hline B4 & 0.056 & 0.034 & 0.093 & 0.066 & 0.058 & 0.013 & 0.079 & 0.155 & 0.128 & 0.068 & 0.131 & 0.049 \\
\hline B5 & 0.191 & 0.074 & 0.232 & 0.133 & 0.118 & 0.045 & 0.166 & 0.214 & 0.233 & 0.178 & 0.094 & 0.188 \\
\hline B6 & 0.053 & 0.028 & 0.066 & 0.080 & 0.045 & 0.012 & 0.052 & 0.078 & 0.182 & 0.060 & 0.127 & 0.044 \\
\hline B7 & 0.257 & 0.179 & $\mathbf{0 . 2 8 5}$ & 0.233 & $\mathbf{0 . 2 7 2}$ & 0.028 & 0.147 & 0.237 & $\mathbf{0 . 3 1 5}$ & 0.182 & 0.161 & 0.228 \\
\hline B8 & 0.081 & 0.060 & 0.100 & 0.128 & 0.122 & 0.015 & 0.082 & 0.075 & 0.103 & 0.076 & 0.069 & 0.056 \\
\hline B9 & 0.150 & 0.044 & 0.174 & 0.104 & 0.071 & 0.014 & 0.120 & 0.076 & 0.088 & 0.056 & 0.045 & 0.082 \\
\hline B10 & 0.118 & 0.123 & 0.189 & 0.176 & 0.196 & 0.021 & 0.158 & 0.210 & 0.194 & 0.084 & 0.073 & 0.152 \\
\hline B11 & 0.132 & 0.053 & 0.161 & 0.156 & 0.108 & 0.016 & 0.135 & 0.154 & 0.127 & 0.089 & 0.057 & 0.131 \\
\hline B12 & 0.063 & 0.101 & 0.144 & 0.139 & 0.095 & 0.015 & 0.125 & 0.082 & 0.115 & 0.057 & 0.077 & 0.060 \\
\hline
\end{tabular}

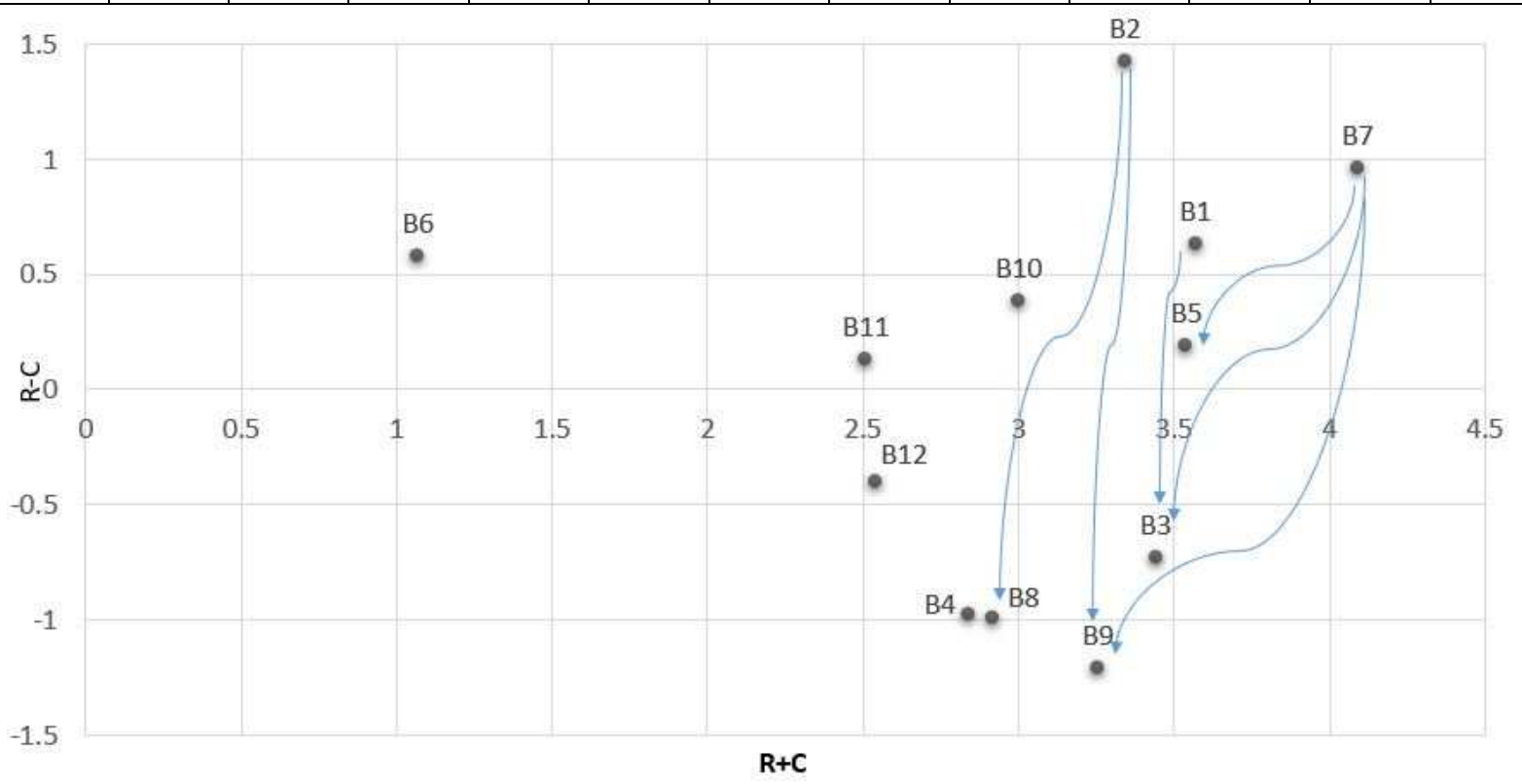

Significant relationships are shown by arrows B1-B3, B2-B8, B2-B9, B7-B3, B7-B5, B7-B9

Figure 2. DEMATEL cause-effect diagram visually categorizes barriers from the technology provider's perspective

Figure 2 contains data that revealed that B2 (Lack of regulatory pressures) and B7 (Lack of environmental education and culture of environmental protection) as the most significant cause barriers, because their (R-C) values are the greatest. This suggests that, from the viewpoint of the technology provider, potential users lack both external pressures and internal motivation to employ smart enabling technologies in waste management. B1 (Lack of knowledge of smart waste management) and B6 (Cost and financial challenges) were also found to be significant. This is understandable, given that smart enabling technologies are relatively new, and their application in waste management still at a nascent stage. Also, many 
people do not believe that they will be cost-effective or beneficial to their supply chain's ecoefficiency in the short or even in the longer-term future.

The research revealed that B7 (Lack of environmental education and culture of environmental protection) was the most prominent barrier, because it has the greatest $(\mathrm{R}+\mathrm{C})$ value. It has significant effects on B5 (Lack of market pressures and demands), B3 (Lack of innovation capacity), and B9 (The pursuit of short-term profitability instead of long-term sustainability). Apparently, when there is a lack of environmental education and culture of environmental protection (B7), the public does not care much about waste management. This was also reflected in organizational behaviors, as indicated by data found for B5 (Lack of market pressures and demands) and B9 (The pursuit of short-term profitability instead of long-term sustainability). The significant relationships indicated by arrows in Figure 2 also showed that B9 (The pursuit of short-term profitability instead of long-term sustainability) is an effect barrier, and is influenced by B2 (Lack of regulatory pressures) and B7 (Lack of environmental education and culture of environmental protection). B8 (Lack of stakeholder cooperation, including service provider co-operation) is influenced by B2 (Lack of regulatory pressures). Clearly, the unsustainable organizational behaviors reflected in B9 and B8 could be changed if the key causal barriers B2 (Lack of regulatory pressures) and B7 (Lack of environmental education and culture) were addressed effectively.

\subsubsection{Results from the Technology User's Perspective}

Table 4 and Figure 3 present the results from the perspective of the technology user. The threshold value was 0.209 for determining a significant relationship.

Table 4. Total relation matrix shows the overall impact relationships among the barriers from the technology user's perspective

\begin{tabular}{|l|l|l|l|l|l|l|l|l|l|l|l|l|}
\hline & B1 & B2 & B3 & B4 & B5 & B6 & B7 & B8 & B9 & B10 & B11 & B12 \\
\hline B1 & 0.091 & 0.039 & 0.152 & 0.199 & 0.091 & $\mathbf{0 . 2 4 6}$ & 0.106 & 0.080 & 0.079 & 0.084 & 0.148 & 0.195 \\
\hline B2 & 0.050 & 0.029 & 0.052 & 0.060 & 0.043 & 0.160 & 0.089 & 0.066 & 0.166 & 0.038 & 0.061 & 0.067 \\
\hline
\end{tabular}




\begin{tabular}{|l|l|l|l|l|l|l|l|l|l|l|l|l|}
\hline B3 & $\mathbf{0 . 2 1 3}$ & 0.069 & 0.102 & $\mathbf{0 . 2 4 2}$ & 0.102 & $\mathbf{0 . 2 7 5}$ & 0.080 & 0.177 & 0.173 & 0.133 & 0.103 & 0.119 \\
\hline B4 & $\mathbf{0 . 2 1 0}$ & 0.065 & 0.209 & 0.129 & 0.126 & $\mathbf{0 . 2 6 4}$ & 0.078 & 0.144 & 0.091 & 0.096 & 0.096 & 0.174 \\
\hline B5 & 0.082 & 0.056 & 0.084 & 0.102 & 0.054 & 0.155 & 0.035 & 0.116 & 0.147 & 0.107 & 0.048 & 0.112 \\
\hline B6 & 0.087 & 0.033 & 0.088 & 0.160 & 0.054 & 0.099 & 0.057 & 0.116 & 0.137 & 0.071 & 0.104 & 0.057 \\
\hline B7 & 0.122 & 0.029 & 0.124 & 0.104 & 0.051 & 0.117 & 0.036 & 0.051 & 0.075 & 0.066 & 0.067 & 0.174 \\
\hline B8 & 0.041 & 0.044 & 0.045 & 0.115 & 0.040 & 0.127 & 0.025 & 0.047 & 0.045 & 0.120 & 0.059 & 0.041 \\
\hline B9 & 0.126 & 0.093 & 0.126 & 0.113 & 0.140 & 0.198 & 0.065 & 0.091 & 0.076 & 0.078 & 0.078 & 0.090 \\
\hline B10 & 0.077 & 0.041 & 0.102 & 0.184 & 0.151 & 0.207 & 0.041 & 0.163 & 0.131 & 0.064 & 0.113 & 0.124 \\
\hline B11 & 0.088 & 0.055 & 0.121 & 0.141 & 0.108 & 0.189 & 0.060 & 0.123 & 0.089 & 0.076 & 0.050 & 0.060 \\
\hline B12 & 0.136 & 0.057 & 0.161 & 0.178 & 0.114 & 0.173 & 0.065 & 0.069 & 0.093 & 0.077 & 0.055 & 0.072 \\
\hline
\end{tabular}

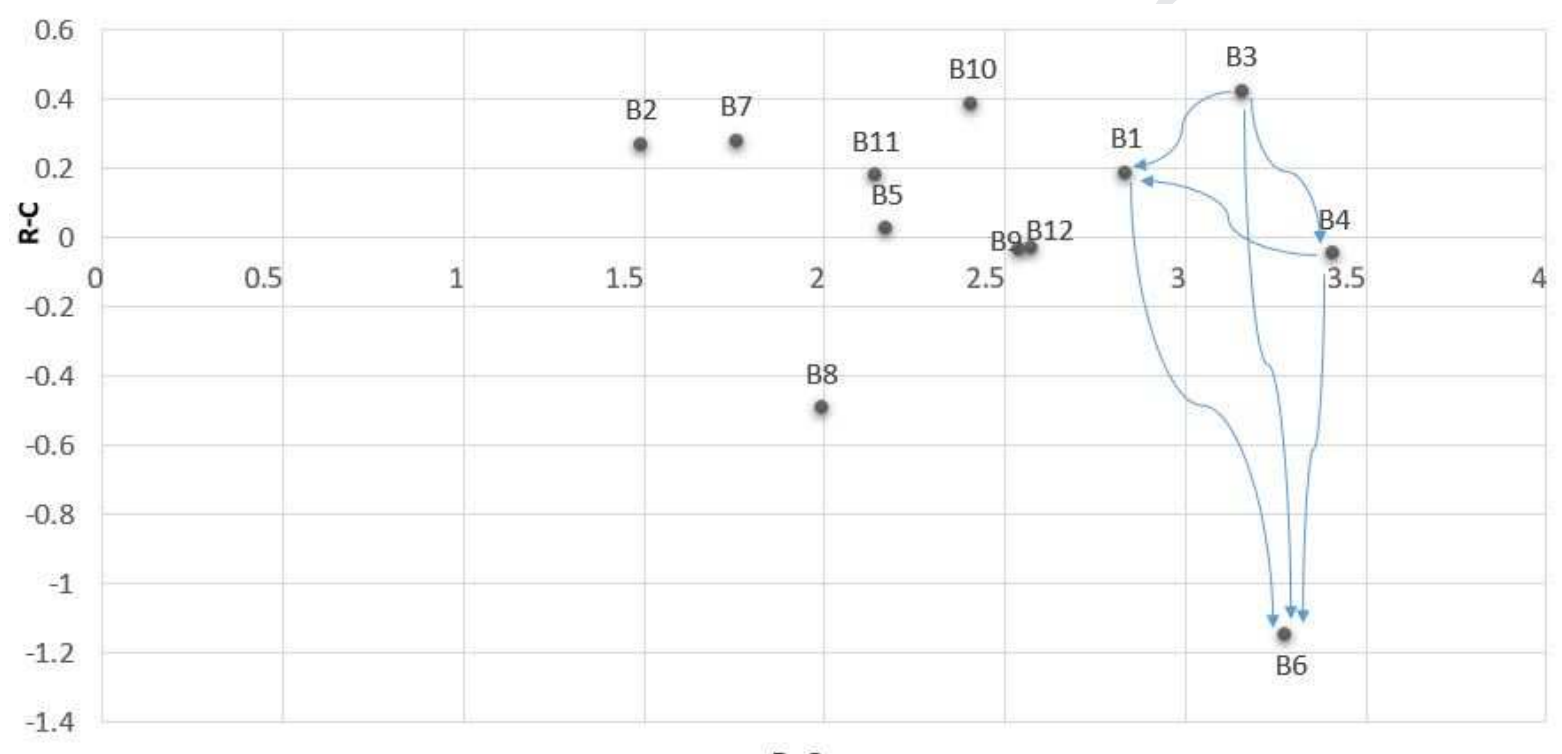

$\mathrm{R}+\mathrm{C}$

Significant relationships are shown by arrows B1-B6, B3-B1, B3-B4, B3-B6, B4-B1, B4-B6

Figure 3. DEMATEL cause-effect diagram visually categorizes barriers from the technology user's perspective

Figure 3 shows the four most significant causal barriers to smart waste management from the perspective of the technology user: B3 (Lack of innovation capacity), B10 (Lack of cluster effect), B2 (Lack of regulatory pressures), and B7 (Lack of environmental education and culture of environmental protection). Apparently, the technology user shares the understanding of the provider that B2 and B7 are significant. However, the user gives more weight to the innovation challenge as reflected in B3 (Lack of innovation capacity) and the operational challenges as reflected in B10 (Lack of cluster effect). This is reasonable, as the 
user does not have a core competence in innovation, and must address the operational challenge of lacking cluster effect when adopting smart waste management solutions.

The four most prominent barriers, judged by how high their $(\mathrm{R}+\mathrm{C})$ were found to be: $\mathrm{B} 4$ (Difficulties in technologies and their applications), B6 (Cost and financial challenges), B3 (Lack of innovation capacity), and B1 (Lack of knowledge of smart waste management). Although B6 (Cost and financial challenges) was prominent, it is an effect barrier because of a negative (R-C) value. It is highly dependent on the other three prominent barriers. This implies that B6 (cost and financial challenges), despite its prominence, can be overcome when an organization has enough innovation capacity, expertise, and knowledge of smart enabling technologies. This is because, when an organization has relevant expertise and when technologies are used effectively, the cost of implementing smart waste management solutions can be more than offset by the financial benefits. A good example can be found in the implementation of IoT-enabled accountability for source separation of household waste in a residential community in Ningbo, Zhejiang province in China. The cost of a countrywide implementation is only about $1 / 36$ of the total economic benefit (Zhang et al., 2019).

\subsubsection{Results from the Governmental Agency's Perspective}

Table 5 and Figure 4 present the results from the perspective of the governmental agency which oversees environmental protection and waste management. The threshold value was 0.274 for determining a significant relationship.

Table 5. Total relation matrix shows the overall impact relationships among the barriers from the governmental agency's perspective

\begin{tabular}{|l|l|l|l|l|l|l|l|l|l|l|l|l|}
\hline & B1 & B2 & B3 & B4 & B5 & B6 & B7 & B8 & B9 & B10 & B11 & B12 \\
\hline B1 & 0.082 & 0.070 & 0.227 & $\mathbf{0 . 3 0 3}$ & 0.101 & 0.093 & 0.151 & 0.139 & 0.150 & 0.190 & 0.179 & 0.200 \\
\hline B2 & 0.097 & 0.064 & 0.124 & 0.173 & 0.180 & 0.103 & 0.080 & 0.137 & 0.228 & 0.220 & 0.208 & 0.113 \\
\hline B3 & 0.059 & 0.075 & 0.084 & 0.258 & 0.065 & 0.101 & 0.061 & 0.178 & 0.121 & 0.168 & 0.110 & 0.086 \\
\hline B4 & 0.071 & 0.078 & 0.098 & 0.129 & 0.092 & 0.173 & 0.095 & 0.182 & 0.136 & 0.127 & 0.161 & 0.069 \\
\hline B5 & 0.219 & 0.191 & $\mathbf{0 . 2 7 7}$ & 0.247 & 0.104 & 0.105 & 0.174 & 0.272 & 0.273 & 0.206 & 0.212 & 0.196 \\
\hline
\end{tabular}




\begin{tabular}{|l|l|l|l|l|l|l|l|l|l|l|l|l|}
\hline B6 & 0.131 & 0.074 & 0.175 & $\mathbf{0 . 3 3 0}$ & 0.114 & 0.102 & 0.164 & 0.263 & 0.252 & 0.173 & 0.229 & 0.129 \\
\hline B7 & 0.175 & 0.183 & 0.258 & 0.274 & 0.122 & 0.132 & 0.096 & 0.189 & 0.261 & 0.187 & 0.206 & 0.256 \\
\hline B8 & 0.081 & 0.065 & 0.182 & 0.212 & 0.145 & 0.104 & 0.101 & 0.132 & 0.182 & 0.254 & 0.097 & 0.080 \\
\hline B9 & 0.182 & 0.061 & 0.226 & 0.273 & 0.077 & 0.114 & 0.108 & 0.202 & 0.115 & 0.197 & 0.133 & 0.117 \\
\hline B10 & 0.101 & 0.086 & 0.135 & 0.158 & 0.141 & 0.094 & 0.097 & 0.217 & 0.137 & 0.109 & 0.116 & 0.104 \\
\hline B11 & 0.141 & 0.052 & 0.178 & 0.216 & 0.064 & 0.101 & 0.097 & 0.183 & 0.172 & 0.138 & 0.089 & 0.104 \\
\hline B12 & 0.040 & 0.032 & 0.085 & 0.103 & 0.038 & 0.070 & 0.067 & 0.092 & 0.087 & 0.087 & 0.050 & 0.042 \\
\hline
\end{tabular}

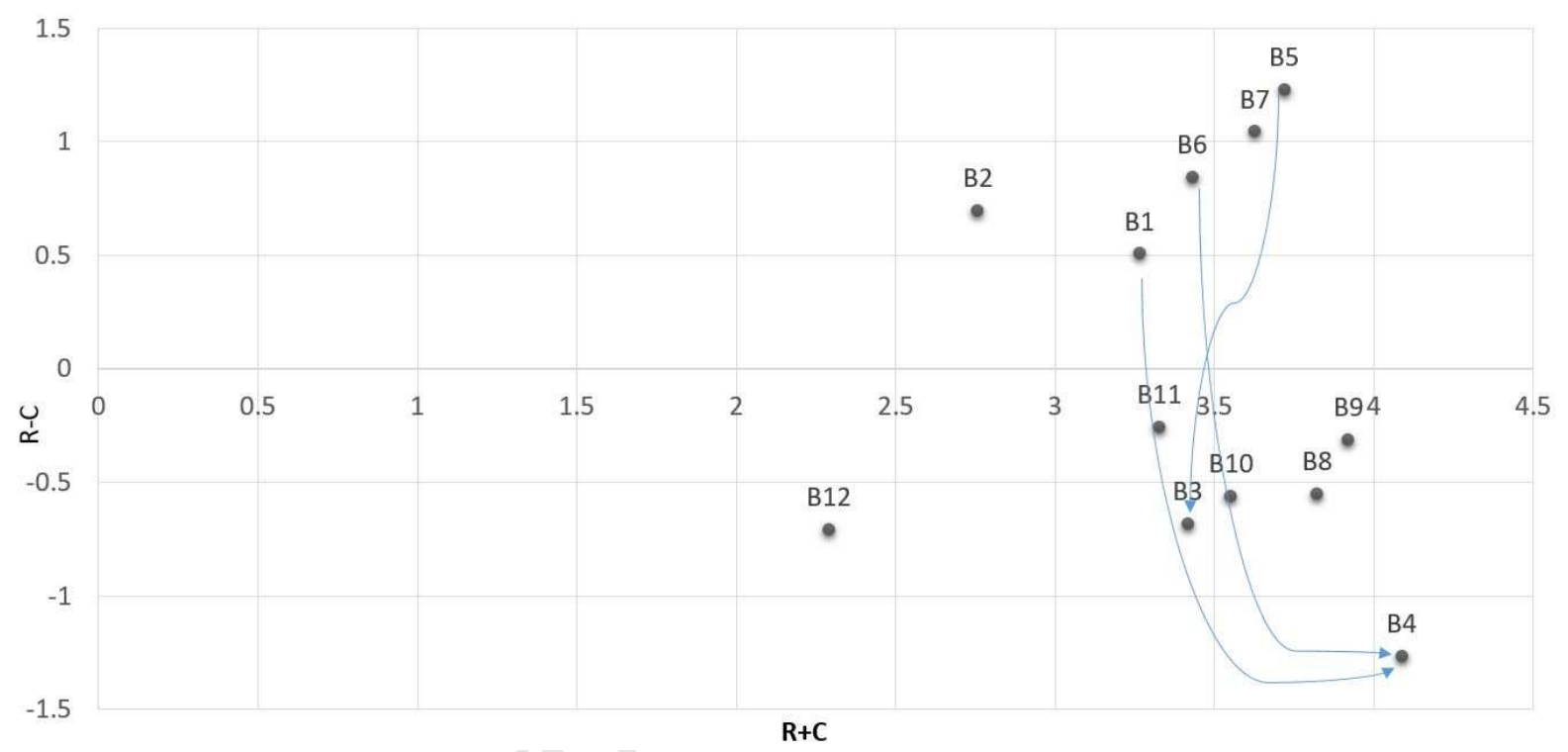

Significant relationships are shown by arrows B1-B4, B5-B3, B6-B4

Figure 4. DEMATEL cause-effect diagram visually categorizes barriers from the governmental agency's perspective

Figure 4 presents information on five causal barriers from the viewpoint of the governmental agency: B5 (Lack of market pressures and demands), B7 (Lack of environmental education and culture of environmental protection), B6 (Cost and financial challenges), B2 (Lack of regulatory pressures), and B1 (Lack of knowledge of smart waste management). Note that in regard to three (B1, B2, B7) of these, the governmental agency agrees with the other two types of stakeholder. However, the governmental agency rated B5 (Lack of market pressures and demand) as the most significant causal barrier. It appears that it places greater responsibility on the market, although it also acknowledges its own responsibility. 
The most prominent barrier, judged by the how high the $(\mathrm{R}+\mathrm{C})$ values were, was $\mathrm{B} 4$ (Difficulties in technologies and their applications), but it is an effect barrier because of its negative (R-C) value. It is highly dependent on B6 (Cost and financial challenges) and B1 (Lack of knowledge of smart waste management). These findings suggested that, although there are technical challenges associated with implementing smart waste management solutions, they can be overcome if there is a commitment of financial resources and expertise. Lack of market pressures and demand (B5) have direct impacts on lack of innovation capacity (B3), which suggests that innovation is mainly driven by the needs of the market.

\subsubsection{Summary of Findings}

The results of the analyses revealed similarities in the responses of the three types of stakeholder, in that they all believed that B1 (Lack of knowledge of smart waste management), B2 (Lack of regulatory pressures), and B7 (Lack of environmental education and culture of environmental protection) are important causal barriers. There were differences among their perspectives. In comparison with the technology provider, the user gave more weight to B3 (Lack of innovation capacity) and B4 (Difficulties in technologies and their applications). This is not a surprise, given that technology users are less adept in keeping up with the rapidly-evolving smart enabling technologies than providers. The governmental agency respondents gave more weight to B5 (Lack of market pressures and demands). This is probably due to their biases, or due to a governmental organization's natural tendency to justify itself by pushing more responsibility onto the market, which has a direct influence on the use of smart waste management technologies.

Both the technology user and the governmental agency personnel identified B4 (Difficulties in technologies and their applications) as the most prominent barrier. This is reasonable, because neither of these stakeholders is specialized in smart enabling technologies, so they sense more challenges in the technical dimensions. In contrast, the technology provider rated 
the same barrier as an effect barrier, making it less important, and in fact did not rate it as prominent at all. Instead, it rated B7 (Lack of environmental education and culture of environmental protection) as the most prominent. This suggests that, from the perspective of the technology provider, technological challenges are not a problem; rather, the lack of demand and its root cause, lack of environmental education and culture of environmental protection, are more important barriers. The finding about B6 (Cost and financial challenges) also deserves attention because it was identified as a prominent barrier by the technology user and a causal barrier by the governmental agency.

\section{Discussion}

The results and findings presented in this article provide insights from three different types of representative stakeholders: a technology provider, a technology user, and a governmental agency, which oversees environmental protection and waste management. On this basis, the authors of this article proposed several propositions: The first was that the lack of pressures from external stakeholders, including the regulatory bodies and the markets (B2 and B5), was at that time a fundamental barrier and a reason for the failure in the promotion of smart enabling technologies for improving waste management. The second was that the lack of internal motivation, which was attributed to the lack of environmental education and culture of environmental protection (B7), was another fundamental barrier. The third was that the lack of knowledge of smart waste management (B1) was a barrier as the markets are still at a nascent stage. The fourth was that the cost and financial challenges (B6) associated with implementing smart waste management solutions were important factors. Last but not least, technical difficulties associated with smart waste management (B4) were considered a prominent barrier by the potential and actual technology users, but not by the providers. 
Based on these general propositions, the authors of this research derived practical and theoretical implications, which are presented in the following two subsections.

\subsection{Practical implications}

The key causal barriers, B2 (Lack of regulatory pressures), B5 (Lack of market pressures and demands), and B7 (Lack of environmental education and culture of environmental protection), are of fundamental importance, as they will affect the system over the long-term. In order to overcome these three barriers, it is essential for the Chinese government to take an approach of active involvement. The Chinese National Development and Reform Commission (NDRC) was charged with the responsibility of promoting CE. It should intensify its regulatory pressures, since CE has already been legislated in China in 2008. Over the past decade, China has made some progress in incorporating environmental education into its national educational curricula. However, a cultural transformation often takes several decades. Therefore, the NDRC must continue to work with the Ministry of Education to further integrate $\mathrm{CE}$ into the education of the younger generations. It is also essential to implement 'life-long-learning' programs for all adult members of the society by promoting CE through multiple media channels in order to guide them to behave in a more environmentally sustainable way. Behavioral changes are more likely to happen after all society members are educated on the benefits of prevention and minimization of energy and material waste within the context of CE.

In late 2018, the world's leading climate scientists urged rapid and unprecedented changes in all aspects of society, including waste management, in order to limit global warming to 1.5 ${ }^{\circ} \mathrm{C}$ and ensure a more sustainable and equitable society (IPCC, 2018). There is therefore, an urgent need for the government to develop and implement policies to improve materials and energy use efficiency, and to reduce toxicity and fossil carbon footprint. On top of monitoring and enforcing policy implementation, there is also a need to facilitate continuous 
improvement of the system to accelerate the transition to equitable, livable, sustainable post fossil carbon societies. For example, the educational institutions may teach students and companies at the academic level, design courses to develop product-service systems (PSS) for contributing to CE (Ellen MacArthur Foundation, 2013). They should also support academic research on the new concepts, tools, processes and products to ensure widespread implementation of CE. Besides educational institutions, all societal organizations and individual members including farmers and workers in the industrial zones, have a role to play in improving waste management and fighting climate change.

The prominent barriers require immediate attention, as they will have the greatest overall effects on the system in the short term. Overall, technical difficulties (B4) hinder the actual and potential users of smart waste management solutions from implementing them. The markets for smart waste management are still in their infancy, so there is a serious lack of relevant knowledge (B1) on the part of the actual and potential users. To overcome these barriers, the technology providers must effectively engage in educating potential customers on the benefits and the basics of smart waste management solutions. Costs and other financial challenges (B6) are other impediments to the uptake of smart waste management solutions which are important to address in the short term. The Chinese government may consider offering financial incentives/assistance, in the forms of technology grants or tax rebates, to encourage the use of the latest smart enabling technologies for improving the effectiveness of waste management operations.

\subsection{Theoretical implications}

Many authors of sustainability literature have used the stakeholder theory as a lens through which to study firms' adoption of sustainability practices (Busse, 2016; Foerstl et al., 2010). The research for this article revealed that lack of regulatory pressures (B2) and lack of market pressures and demands (B5) are key barriers to the use of smart waste management solutions 
for improving environmental performance. This research confirms the relevance of the stakeholder theory for sustainability research.

Additionally, the resource-based view (RBV) of firms theorizes how they can and do gain sustained competitive advantages by drawing on distinctive resources and capabilities (Barney, 1991; Rugman and Verbeke, 2002). In the RBV theory, resources include "all assets, capabilities, organizational processes, firm attributes, information, knowledge, etc. controlled by a firm that enable the firm to conceive of and to implement strategies that improve its efficiency and effectiveness" (Barney, 1991). The research upon which this paper was developed, documented how lack of knowledge of smart waste management (B1) and costs and financial challenges (B6) are important barriers. This finding is accord with the theoretical proposition of the RBV, and suggests that the RBV may also be a useful theoretical framework for studying sustainability initiatives.

This research on ways to improve waste management was undertaken from a CE perspective. The old vision of waste management was to develop more efficient and effective waste management systems. Such a philosophy, however, does not and will never lead to CEs. A pure CE should design the products/services and supply chain processes in such a way that no waste is generated. All product/service combinations should be designed to be provided in such a way that the products can be upgraded, reused, repaired, remanufactured, and/or totally recycled, thereby dramatically reducing or eliminating the need for end-of-the-pipe or end-of-life waste management processes and technologies. Therefore, focusing on improving waste management is a continuation of the old vision. Of course, there will be waste, and we will still need to optimise management of it as we strive to achieve the CE vision. Consequently, truly smart waste management should evolve towards smart resource management based on the technical, biological, ecological, economic and ethical attributes of resources. Multiple supply chain stakeholders must co-operate, with a multi-generational 
perspective, to design products/services and their supply chains for a transition to circular supply chain management (Genovese et al., 2017; Mangla et al., 2018; Farooque et al., 2019). This must also be contextualized by a sense of urgency to develop and implement processes, procedures, policies, and lifestyles that will help to: "Accelerate the transition to equitable, sustainable, livable, post-fossil carbon societies."

\section{Conclusions}

Responsible and effective waste management has become increasingly challenging within many economies due to the increasing amounts of diverse types of waste generated. The CE concepts are providing some new insights and are beginning to lead to technical approaches, which are potentially, much more efficient than those presently dominant in societies globally. The authors hope that this article will help societal leaders to make effective and rapid progress towards overcoming the barriers to implementing responsible waste management with circular usage of currently wasted resources from our product/service systems. Additionally, the authors hope that we can collectively make a transition to zerowaste systems, which are also post-fossil carbon societies.

Currently, the status quo of waste management is very far from a CE vision. Rapidlyevolving smart enabling technologies can catalyze and support the transformation of waste management into true CEs. However, many barriers are slowing down implementation of improved waste resource management. The barriers will be difficult to overcome because they are often intertwined with each other. However, the authors of this paper hope that their efforts will be useful for identifying and prioritizing actions to overcome the barriers to smart waste management in China, which is one of the three countries which has legislated the implementation of CE. 
The authors of this paper make several original contributions. First, it is a pioneering work on smart waste management. More and more smart applications are gradually being developed and implemented within various industries in recent years, but the academic research in this promising area was lagging. This paper provides a definition of smart waste management and can serve to stimulate and guide further research studies. Second, to the best of our knowledge, this paper is the first focused upon documenting and overcoming the barriers to implementation of smart waste management systems. Smart enabling technologies have great potential for improving the performance of waste management activities, but there are many barriers that hinder their implementation. This research is timely because it provides knowledge on the typical barriers to adopting smart waste management in China, the world's largest developing country, and one that faces huge challenges in waste management. The resulting practical implications are beneficial for policy-making and provide managerial decision-support. Third, this research employed a mixed-methods approach to first shortlist barriers (based on interviews with experienced practitioners) and then to quantify their causal-effect relationships through a scientific prioritization technique called fuzzy DEMATEL. This methodology provided more credible insights than simple qualitative or quantitative methods. Last but not least, this research has important theoretical implications. It affirms the relevance of the stakeholder theory and RBV for sustainability research. It highlights an important research direction that waste management for CE must address, together with product and supply chain design, to achieve the circularity of materials, to use energy more efficiently, and to accelerate the transition to equitable, sustainable, livable, post-fossil carbon CE societies within the context of urgent climate change-related dangers.

This research has its limitations. It focused within the context of China, which has a unique culture and is quite different from many countries. Because culture influences how waste management technology is adopted, it is necessary to expand this type of research into 
the barriers in different countries and cultures and into ways of overcoming those barriers. As the CE implementation progresses further in China, the barriers to smart waste management may evolve over time so there is a need to update the study in the future. This research was based upon quantitative analyses of barriers based on three representative stakeholders: a technology provider, a technology user (which was a property development and construction firm), and a governmental agency (which oversees environmental protection and waste management). Future research must consider testing relevant theoretical propositions through a large-scale survey which includes more participants and multiple industrial sectors among the users of smart waste management solutions.

\section{Acknowledgements:}

The authors would like to acknowledge partial financial support from the National Natural

Science Foundation of China (51875251), Natural Science Foundation of Guangdong Province of China (Key program 2016A030311041), the National Ministry of Education "Blue Fire Project" (Huizhou) Industry-University-Research Joint Innovation Fund (CXZJHZ201722), and the Fundamental Research Funds for the Central Universities (11618401).

\section{Appendix 1 - Interview protocol}

1. Is your organization involved in the practice of smart waste management?

2. If yes, what type of equipment/systems are available? List out the smart enabling technologies employed and describe them.

3. Can you please give some examples of how the technologies are used in waste management? 
4. If applicable, what obstacles/barriers did you face in employing smart enabling technologies?

5. If applicable, how did you effectively manage/overcome these barriers to improve your overall performance?

Appendix 2 - Profile of participants in the qualitative research phase

\begin{tabular}{|c|c|c|c|}
\hline $\begin{array}{l}\text { Participant } \\
\text { Number }\end{array}$ & Industry type & Position of participant & $\begin{array}{c}\text { Work } \\
\text { experience }\end{array}$ \\
\hline $\mathrm{n} 1$ & $\begin{array}{l}\text { Manufacturing (smart waste } \\
\text { equipment/systems) }\end{array}$ & Vice-general manager & 15 years \\
\hline $\mathrm{n} 2$ & $\begin{array}{c}\text { Manufacturing (smart waste } \\
\text { equipment/systems) }\end{array}$ & Administrative specialist & 4 years \\
\hline n3 & Logistics & General manager & 18 years \\
\hline n4 & Government & $\begin{array}{l}\text { Secretary of the community } \\
\text { Party committee }\end{array}$ & 31 years \\
\hline n5 & Healthcare & secretary & 6 years \\
\hline n6 & $\begin{array}{l}\text { Property development and } \\
\text { construction }\end{array}$ & Administrative director & 5 years \\
\hline $\mathrm{n} 7$ & Manufacturing & Chief human resource officer & 12 years \\
\hline n8 & Manufacturing & $\begin{array}{c}\text { Chairman of the Workers' } \\
\text { Union }\end{array}$ & 20 years \\
\hline n9 & Manufacturing & Engineer & 10 years \\
\hline $\mathrm{n} 10$ & Manufacturing & $\begin{array}{l}\text { Security and Environmental } \\
\text { Management Director }\end{array}$ & 11 years \\
\hline $\mathrm{n} 11$ & Manufacturing & General manager & 15 years \\
\hline $\mathrm{n} 12$ & Manufacturing & Sales director & 30 years \\
\hline n13 & Manufacturing & Executive & 30 years \\
\hline n14 & Manufacturing & Secretary & 5 years \\
\hline
\end{tabular}

Appendix 3 - Profile of participants in the quantitative research phase 


\begin{tabular}{|c|c|c|c|}
\hline $\begin{array}{l}\text { Participant } \\
\text { Number }\end{array}$ & Industry type & Position of participant & $\begin{array}{c}\text { Work } \\
\text { experiences }\end{array}$ \\
\hline p1 & $\begin{array}{c}\text { Manufacturing (smart waste } \\
\text { equipment/systems) }\end{array}$ & Vice-general manager & 15 years \\
\hline $\mathrm{p} 2$ & $\begin{array}{l}\text { Property development and } \\
\text { construction }\end{array}$ & Buyer & 5 years \\
\hline p3 & Government & Government administrator & 10 years \\
\hline
\end{tabular}

\section{References}

Aazam, M., St-Hilaire, M., Lung, C. H., Lambadaris, I., (2016). Cloud-based smart waste management for smart cities. 2016 IEEE 21st International Workshop on Computer Aided Modelling and Design of Communication Links and Networks (CAMAD). Toronto, ON, Canada. https://doi.org/10.1109/CAMAD.2016.7790356

Albino, V., Berardi, U., Dangelico, R. M., 2015. Smart cities: Definitions, dimensions, performance, and initiatives. Journal of urban technology. 22(1), 3-21.

Aljerf, L. (2018). Data of thematic analysis of farmer' s use behavior of recycled industrial wastewater. Data in Brief, 21, 240-250.

Anagnostopoulos, T., Zaslavsky, A., Kolomvatsos, K., et al., 2017. Challenges and opportunities of waste management in IoT-enabled smart cities: a survey. IEEE Transactions on Sustainable Computing, 2(3), 275-289. https://doi.org/10.1109/TSUSC.2017.2691049

Arena, U., 2012. Process and technological aspects of municipal solid waste gasification: a review. Waste management, 32(4), 625-639.

Atzori, L., Iera, A., Morabito, G., 2010. The internet of things: a survey. Computer networks, 54(15), 2787-2805.

Bai, C., Sarkis, J., Dou, Y., 2017. Constructing a process model for low-carbon supply chain cooperation practices based on the DEMATEL and the NK model. Supply Chain Management: An International Journal, 22, 237-257.

Barney, J., 1991. Firm resources and sustained competitive advantage. Journal of Management, 17, 99-120.

Batista, L., Bourlakis, M., Liu, Y., Smart, P., Sohal, A., 2018. Supply chain operations for a circular economy. Production Planning \& Control, 29(6), 419-424. https://doi.org/10.1080/09537287.2018.1449267 
Bell E., Bryman A., Harley B., 2018. Business Research Methods. $5^{\text {th }}$ Edition. UK: Oxford University Press.

Busse, C., 2016. Doing well by doing good? the self-interest of buying firms and sustainable supply chain management. Journal of Supply Chain Management, 52(2), 28-47. https://doi.org/10.1111/jscm.12096

Cerchecci, M., Luti, F., Mecocci, A., Parrino, S., Peruzzi, G., \& Pozzebon, A. (2018). A low power IoT sensor node architecture for waste management within smart cities context. Sensors, 18(4), 1282.

Chertow, M. R., 2007. "Uncovering" industrial symbiosis. Journal of Industrial Ecology, 11(1), 11-30.

Chi, X., Streicher-Porte, M., Wang, M. Y. L., Reuter, M. A., 2011. Informal electronic waste recycling: A sector review with special focus on China. Waste Management, 31(4), 731742. https://doi.org/10.1016/j.wasman.2010.11.006

Chu, Z., Wu, Y., Zhuang, J., 2017. Municipal household solid waste fee based on an increasing block pricing model in Beijing, China. Waste Management \& Research, 35(3), 228-235.

Deng, H., 1999. Multi criteria analysis with fuzzy pair wise comparison. International Journal of Approximate Reasoning, 21(3), 215-231.

de Souza Melaré, A. V., González, S. M., Faceli, K., Casadei, V., 2017. Technologies and decision support systems to aid solid-waste management: a systematic review. Waste management, 59, 567-584.

Ellen MacArthur Foundation, 2013. Towards the circular economy. Retrieved from https://www.ellenmacarthurfoundation.org/assets/downloads/publications/EllenMacArthur-Foundation-Towards-the-Circular-Economy-vol.1.pdf

Esmaeilian, B., Wang, B., Lewis, K., Duarte, F., Ratti, C., Behdad, S., 2018. The future of waste management in smart and sustainable cities: A review and concept paper. Waste Management, 81(November), 177-195.

Farooque, M., Zhang, A., 2017. Supply chain management for the circular economy: a review and a classification of terms. Proceedings of the 15th ANZAM Operations, Supply Chain and Services Management Symposium, Queenstown, New Zealand. 9-10.

Farooque, M., Zhang, A., Thurer, M., Qu T., Huisingh, D., 2019. Circular supply chain management: A definition and structured literature review. Journal of Cleaner Production, 228, 882-900.

Foerstl, K., Reuter, C., Hartmann, E., Blome, C., 2010. Managing supplier sustainability risks in a dynamically changing environment - Sustainable supplier management in the 
chemical industry. Journal of Purchasing and Supply Management, 16(2), 118-130. https://doi.org/10.1016/j.pursup.2010.03.011

Fuss, M., Barros, R. T. V., Poganietz, W. R., 2018. Designing a framework for municipal solid waste management towards sustainability in emerging economy countries - an application to a case study in Belo Horizonte (Brazil). Journal of Cleaner Production, 178, 655-664.

Genovese, A., Acquaye, A. A., Figueroa, A., Koh, S. C. L., 2017. Sustainable supply chain management and the transition towards a circular economy: evidence and some applications. Omega, 66, 344-357. https://doi.org/10.1016/j.omega.2015.05.015

Gentles, S. J., Charles, C., Ploeg, J., McKibbon, K., 2015. Sampling in qualitative research: insights from an overview of the methods literature. The Qualitative Report, 20(11), 17721789.

Ghisellini, P., Cialani, C., Ulgiati, S., 2016. A review on circular economy: the expected transition to a balanced interplay of environmental and economic systems. Journal of Cleaner Production, 114, 11-32. https://doi.org/10.1016/j.jclepro.2015.09.007

Giunipero, L. C., Hooker, R. E., Denslow, D., 2012. Purchasing and supply management sustainability: drivers and barriers. Journal of Purchasing and Supply Management, 18(4), 258-269. https://doi.org/10.1016/j.pursup.2012.06.003

Glouche, Y., Couderc, P., 2013. A smart waste management with self-describing objects. Presented at the Second International Conference on Smart Systems, Devices and Technologies (SMART'13), Rome, Italy.

Gölcük, İ., Baykasoğlu, A., 2016. An analysis of DEMATEL approaches for criteria interaction handling within ANP. Expert Systems with Applications, 46, 346-366.

Govindan, K., Chaudhuri, A., 2016. Interrelationships of risks faced by third-party logistics service providers: a DEMATEL based approach. Transportation Research Part E: Logistics and Transportation Review, 90, 177-195.

Govindan, K., Hasanagic, M., 2018. A systematic review on drivers, barriers, and practices towards circular economy: a supply chain perspective. International Journal of Production Research, 56(1-2), 278-311. https://doi.org/10.1080/00207543.2017.1402141

Gu, B., Wang, H., Chen, Z., et al., (2015). Characterization, quantification and management of household solid waste: a case study in China. Resources, Conservation and Recycling, 98, 67-75.

Gutierrez, J. M. Jensen, M., Heniusa, M., Riazc, T., (2015). Smart waste collection system based on location intelligence. Procedia Computer Science, 61, 120-127.

Hannan, M. A., Abdulla Al Mamun, M., Hussain, A., Basri, H., Begum, R. A., 2015. A review on technologies and their usage in solid waste monitoring and management 
systems: issues and challenges. Waste Management, 43, 509-523. https://doi.org/10.1016/j.wasman.2015.05.033

Hazen, B. T., Mollenkopf, D. A., Wang, Y., 2017. Remanufacturing for the circular economy: an examination of consumer switching behavior. Business Strategy and the Environment, 26(4), 451-464. https://doi.org/10.1002/bse.1929

Hong, I., Park, S., Lee, B., Lee, J., Jeong, D., Park, S., 2014. IoT-based smart garbage system for efficient food waste management. The Scientific World Journal, 1-13.

IPCC. (2018). Summary for policymakers of IPCC special report on global warming of $1.5^{\circ} \mathrm{C}$ approved by governments. Publisher: Intergovernmental Panel on Climate Change (IPCC). Accessed on the $21^{\text {st }}$ February, 2019. https://www.ipcc.ch/2018/10/08/summary-forpolicymakers-of-ipcc-special-report-on-global-warming-of-1-5c-approved-bygovernments/.

Jacobsen, R., Willeghems, G., Gellynck, X., \& Buysse, J. (2018). Increasing the quantity of separated post-consumer plastics for reducing combustible household waste: The case of rigid plastics in Flanders. Waste management, 78, 708-716.

Jensen, J. P., Remmen, A., 2017. Enabling circular economy through product stewardship. Procedia Manufacturing, 8, 377-384. https://doi.org/10.1016/j.promfg.2017.02.048

Jha, S. K., Bilalovic, J., Jha, A., Patel, N., Zhang, H., 2017. Renewable energy: present research and future scope of Artificial Intelligence. Renewable and Sustainable Energy Reviews, 77 (September), 297-317.

Kassinis, G., Vafeas, N., 2006. Stakeholder pressures and environmental performance. Academy of Management Journal, 49(1), 145-159. https://doi.org/10.5465/amj.2006.20785799

Kaur, J., Sidhu, R., Awasthi, A., Chauhan, S. Goyal, S., 2017. A DEMATEL based approach for investigating barriers in green supply chain management in Canadian manufacturing firms. International Journal of Production Research, 1-21.

Li, W. and W. Lin (2016), 'Circular Economy Policies in China', in Anbumozhi, V. and J. Kim (eds.), Towards a Circular Economy: Corporate Management and Policy Pathways. ERIA Research Project Report 2014-44, Jakarta: ERIA, pp.95-111.

Lin, R.-J., 2013. Using fuzzy DEMATEL to evaluate the green supply chain management practices. Journal of Cleaner Production, 40, 32-39.

Huo, L., (2019), 10 urban areas to pilot China's 'no-waste city' plan, Retrieved from http://english.gov.cn/policies/policy_watch/2019/01/28/content_281476498146346.htm

Liu, S., Zhang, Y., Liu, Y., Wang, L., Wang, X.V., 2019. An 'Internet of Things' enabled dynamic optimization method for smart vehicles and logistics tasks. Journal of Cleaner Production, 215, 806-820. 
Luoma, P., Meixell, M. J., 2015. Stakeholder pressure in sustainable supply chain management: A systematic review. International Journal of Physical Distribution \& Logistics Management, 45(1/2), 69-89. https://doi.org/10.1108/IJPDLM-05-2013-0155

Mangla, S. K., Luthra, S., Mishra, N., et al., (2018). Barriers to effective circular supply chain management in a developing country context. Production Planning \& Control, 29(6), 551569. https://doi.org/10.1080/09537287.2018.1449265

Masi, D., Kumar, V., Garza-Reyes, J. A., Godsell, J., 2018. Towards a more circular economy: exploring the awareness, practices, and barriers from a focal firm perspective. $\begin{array}{llll}\text { Production } \quad \text { Planning } \quad \text { C } & \text { 539-550. }\end{array}$ https://doi.org/10.1080/09537287.2018.1449246

Mathews, J. A., Tan, H., 2016. Circular economy: lessons from China. Nature, 531, 440-442.

Morrissey, A. J., Browne, J., 2004. Waste management models and their application to sustainable waste management. Waste Management, 24(3), 297-308. https://doi.org/10.1016/j.wasman.2003.09.005

Wolf, J., 2011. Sustainable supply chain management integration: a qualitative analysis of the German manufacturing industry. Journal of Business Ethics, 102(2), 221-235. https://doi.org/10.1007/s10551-011-0806-0

Omar, M. F., Termizi, A. A. A., Zainal, D., Wahap, N. A., Ismail, N. M., Ahmad, N., 2016. Implementation of spatial smart waste management system in malaysia. IOP Conference Series: Earth and Environmental Science, 37, 012059. https://doi.org/10.1088/17551315/37/1/012059.

Othman, S. N., Noor, Z. Z., Abba, A. H., Yusuf, R. O., Hassan, M. A. A., 2013. Review on life cycle assessment of integrated solid waste management in some Asian countries. Journal of Cleaner Production, 41(February), 251-262.

Park, J., Sarkis, J., Wu, Z., 2010. Creating integrated business and environmental value within the context of China's circular economy and ecological modernization. Journal of Cleaner Production, 18(15), 1494-1501. https://doi.org/10.1016/j.jclepro.2010.06.001

Rugman, A. M., Verbeke, A., 2002. Edith Penrose's contribution to the resource-based view of strategic management. Strategic Management Journal, 23, 769-780.

Rauer, J., Kaufmann, L., 2015. Mitigating external barriers to implementing green supply chain management: a grounded theory investigation of green-tech companies' rare earth metals supply chains. Journal of Supply Chain Management, 51, 65-88.

Sarkar, A. N., 2013. Promoting eco-innovations to leverage sustainable development of ecoindustry and green growth. European Journal of Sustainable Development, 2(1), 171-224.

Schafer, B., 2014. D-waste: data disposal as challenge for waste management in the Internet of Things. International Review of Information Ethics, 22(12), 100-106. 
Seçme, N. Y., Bayrakdaroğlu, A., Kahraman, C., 2009. Fuzzy performance evaluation in Turkish banking sector using analytic hierarchy process and TOPSIS. Expert Systems with Applications, 36(9), 11699-11709.

Seuring, S., Müller, M., 2008. From a literature review to a conceptual framework for sustainable supply chain management. Journal of cleaner production, 16(15), 1699-1710.

Shao, J., Taisch, M., Ortega-Mier, M., 2016. A grey-Decision-Making Trial and Evaluation Laboratory (DEMATEL) analysis on the barriers between environmentally friendly products and consumers: practitioners' viewpoints on the European automobile industry. Journal of Cleaner Production, 112, 3185-3194.

Shi, H., Peng, S. Z., Liu, Y., Zhong, P., 2008. Barriers to the implementation of cleaner production in Chinese SMEs: government, industry and expert stakeholders' perspectives. Journal of Cleaner Production, 16, 842-852.

Su, B., Heshmati, A., Geng, Y., Yu, X., 2013. A review of the circular economy in China: moving from rhetoric to implementation. Journal of Cleaner Production, 42, 215-227. https://doi.org/10.1016/j.jclepro.2012.11.020

Tai, J., Zhang, W., Che, Y., Feng, D., 2011. Municipal solid waste source-separated collection in China: A comparative analysis. Waste management, 31(8), 1673-1682.

Taelman, S., Tonini, D., Wandl, A., \& Dewulf, J. (2018). A holistic sustainability framework for waste management in European cities: Concept development. Sustainability, 10(7), 2184

Veleva, V., Bodkin, G., Todorova, S., (2017). The need for better measurement and employee engagement to advance a circular economy: lessons from Biogen's "zero waste" journey. Journal of Cleaner Production, 154, 517-529. https://doi.org/10.1016/j.jclepro.2017.03.177

Venkatesh, V. G., Zhang, A., Luthra, S., Dubey, R., Subramanian, N., Mangla, S., 2017. Barriers to coastal shipping development: an Indian perspective. Transportation Research Part D: Transport and Environment, 52, 362-378.

Walker, H., Di Sisto, L., Mcbain, D., 2008. Drivers and barriers to environmental supply chain management practices: lessons from the public and private sectors. Journal of Purchasing and Supply Management, 14, 69-85.

Wu, W.-W., Lee, Y.-T., 2007. Developing global managers' competencies using the fuzzy DEMATEL method. Expert Systems with Applications, 32(2), 499-507. https://doi.org/10.1016/j.eswa.2005.12.005

Wu, Z., Pagell, M., 2011. Balancing priorities: decision-making in sustainable supply chain management. Journal of Operations Management, 29(6), 577-590. https://doi.org/10.1016/j.jom.2010.10.001 
Wu, W. W., 2012. Segmenting critical factors for successful knowledge management implementation using the fuzzy DEMATEL method. Applied Soft Computing, 12(1), 527535 .

Xiao, S., Dong, H., Geng, Y., Brander, M., 2018. An overview of China's recyclable waste recycling and recommendations for integrated solutions. Resources, Conservation and Recycling, 134(July), 112-120.

Xu, W., Zhou, C., Lan, Y., Jin, J., Cao, A., 2015. An incentive-based source separation model for sustainable municipal solid waste management in China. Waste Management \& Research, 33(5), 469-476.

Zanella, A., Bui, N., Castellani, A., Vangelista, L., Zorzi, M., 2014. Internet of things for smart cities. IEEE Internet of Things journal, 1(1), 22-32.

Zhang, A., Zhong R. Y., Farooque, M., Liu, Y., 2019 Forthcoming. IoT-enabled accountability in source separation of household waste. Journal of Cleaner Production.

Zhang, A., Luo, W., Shi, Y., Chia, S.T., Sim, Z.H.X., 2016. Lean and Six Sigma in logistics: A pilot survey study in Singapore. International Journal of Operations and Production Management, 36(11), 1625-1643.

Zhijun, F., \& Nailing, Y. (2007). Putting a circular economy into practice in China. Sustainability Science, 2(1), 95-101.

Zhu, Q., Sarkis, J., Lai, K.-H., 2014. Supply chain-based barriers for truck-engine remanufacturing in China. Transportation Research Part E: Logistics and Transportation Review, 68, 103-117. 
Highlights

Waste management needs to be smarter for a zero-waste circular economy vision Key barriers to smart waste management in China: Lack of regulatory pressures; Lack of environmental education and culture of environmental protection; Lack of knowledge of smart waste management and lack of market pressures and demands The government must gear up regulatory pressures and environmental education 